\title{
Film Formation and Characterization of Undoped ZnO on M-plane Sapphire by Mist Chemical Vapour Deposition (Mist-CVD) with Different Carrier Gas Flow Rates
}

\author{
Hla Myo Tun ${ }^{1}$, Thant Zin Win², Kensuke Minami ${ }^{3}$, Satomi Teraya ${ }^{3}$, Koushi Okita ${ }^{3}$, \\ Yusui Nakamura ${ }^{3,4}$ \\ ${ }^{1}$ Department of Electronic Engineering, Mandalay Technological University, Mandalay Region, Republic of the Union of Myanmar \\ ${ }^{2}$ Department of Electronic Engineering, Yangon Technological University, Yangon, Myanmar \\ ${ }^{3}$ Graduate School of Science and Technology, Kumamoto University, Kumamoto, Japan \\ ${ }^{4}$ Kumamoto Institute for Photo-Electro Organics, Kumamoto, Japan
}

Email address:

hmyotun@gmail.com (H. M. Tun)

\section{To cite this article:}

Hla Myo Tun, Thant Zin Win, Kensuke Minami, Satomi Teraya, Koushi Okita, Yusui Nakamura. Film Formation and Characterization of Undoped ZnO on M-plane Sapphire by Mist Chemical Vapour Deposition (Mist-CVD) with Different Carrier Gas Flow Rates. Science Research. Vol. 3, No. 6, 2015, pp. 300-303. doi: 10.11648/j.sr.20150306.16

\begin{abstract}
ZnO}$ thin films were deposited on sapphire substrate by mist chemical vapor deposition (mist-CVD) with different flow rate of carrier gas. This is a simple and low cost method for large-area deposition system. In this experiment, zinc chloride solution was used as sources, and the crystal growth was achieved at the growth temperature of $600^{\circ} \mathrm{C}$ and various flow rates of Nitrogen gas. The X-ray diffraction (XRD) spectrum was performed, and the photoluminescence spectra proved near-band-edge emission and strong deep-level emissions. In this work, we obtained the optimum condition for crystal growth of $\mathrm{ZnO}$ on m-plane sapphire, where XRD $\theta-2 \theta$ single peak at m-plane $\mathrm{ZnO}$.
\end{abstract}

Keywords: Film Formation, Characterization, Mist-CVD, ZnO, LED

\section{Introduction}

In recent times, II-VI semiconductor materials have been of great interest due to application for luminescence and ultraviolet (UV) optical devices such as light emitting diodes (LEDs) and laser diodes (LDs) [1]. Zinc Oxide $(\mathrm{ZnO})$ has fascinated extensive consideration due to its greater physical properties and potential technological applications. The wide direct-bandgap of $\mathrm{ZnO}$ is $3.37 \mathrm{eV}$ and it has a large exciton binding energy of $60 \mathrm{meV}$, which errands efficient excitonic emission processes at room temperature and enables devices to purpose at a low threshold voltage. $\mathrm{ZnO}$ (as a group-II oxide) proves enormous assure for applications in blue/UV light emitters and photodetectors, over and above transparent electronics, chemical sensors, spintronics, and varistors. Various techniques, such as magnetron sputtering, reactive evaporation, pulse laser deposition (PLD), metaorganic chemical vapor deposition (MOCVD), molecular bean epitaxy (MBE), spray pyrolysis, and sol-gel can be useful for $\mathrm{ZnO}$ thin films deposition [2].

We have developed a mist-CVD method as a promising technique that allows superior controllability in film deposition at low cost with an uncomplicated system and low energy consumption [3]. In this method, a $60 \mathrm{ml}$ of zinc chloride (zinc compound) solution is ultrasonically atomized to form mist particles of the solution, and the particles are afterward transferred by a carrier gas of nitrogen onto the heat sapphire substrate, forming $\mathrm{ZnO}$ film by pyrolysis and chemical reactions. The fundamental concept may be similar to that of spray pyrolysis, but the main difference is in particle volume and the merits of treating mist particles like nitrogen gas.

In this paper, we report that $\mathrm{ZnO}$ layers deposited on m-plane sapphire substrate by mist chemical vapor deposition (mist-CVD) with different flow rate of carrier gas at $600^{\circ}$ Cexperiments. The optical and structural properties of un-doped $\mathrm{ZnO}$ layer are characterized by scanning electron microscopy (SEM), photoluminescence (PL), film thickness measurement and X-ray diffraction (XRD). Based on the results, it is confirmed that $\mathrm{ZnO}$ films have single orientation of crystal. 


\section{Experiment}

Fig. 1 shows the experimental setup of mist-CVD system for crystal growth of undoped $\mathrm{ZnO}$ films were grown on m-plane sapphire with different flow rate of carrier gas. Deposition of $\mathrm{ZnO}$ thin films was carried at the substrate temperatures of $600^{\circ} \mathrm{C}$ with various gas flow rates of $6 \mathrm{~L} / \mathrm{min}, 8 \mathrm{~L} / \mathrm{min}$ and 10 $\mathrm{L} / \mathrm{min}$ and $60 \mathrm{~mL}$ of zinc chloride solution.

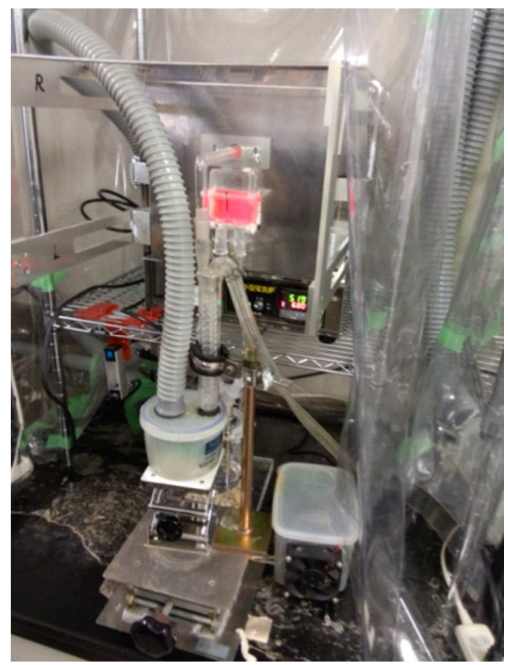

Fig. 1. Experimental Setup.

The photoluminescence spectra were verified by using $\mathrm{He}-\mathrm{Cd}$ Laser which has an excitation wavelength of $325 \mathrm{~nm}$. After the thin film was etched by mixed solution of $\mathrm{CH}_{3} \mathrm{COOH}$ solution, phosphoric acid and pure water and the film thickness was measured by KLA-Tencor. The surface of film morphology was investigated with JEOL JSM7600F (SEM). The X-ray Diffraction (XRD) scan in the $\theta / 2 \theta$ mode was performed to determine the film orientation perpendicular to the film surface.

\section{Results and Discussions}

The deposition condition for experiment is given in Table I.

Table I. Deposition Conditions for Experiment.

\begin{tabular}{ll}
\hline Solution & Zinc Chloride aqueous solution $(\mathbf{0 . 1} \mathbf{~ m o l} / \mathbf{L})$ \\
\hline Deposition Temperature & $600^{\circ} \mathrm{C}$ \\
Flow Rate & $61 / \mathrm{min}, 81 / \mathrm{min}$ and $101 / \mathrm{min}$ \\
Substrate & $\mathrm{m}$-plane Sapphire \\
Solution Amount & $60 \mathrm{ml}$ \\
\hline
\end{tabular}

Fig. 2 shows the photographs of deposited thin films of $\mathrm{ZnO}$ at substrate temperature of $600^{\circ} \mathrm{C}$ with different flow rates for $6 \mathrm{~L} / \mathrm{min}, 8 \mathrm{~L} / \mathrm{min}$ and $10 \mathrm{~L} / \mathrm{min}$ of nitrogen gas. The surface morphologies were characterized by SEM. In case of sample grown at $8 \mathrm{~L} / \mathrm{min}$ and $10 \mathrm{~L} / \mathrm{min}$ of flow rate, the front side of the sample has almost no grain boundary.

In order to characterize the optical properties of $\mathrm{ZnO}$ films deposited on m-plane sapphire, the PL measurements were performed at room temperature and the results are revealed in Fig.3. A weak near-band-edge (NBE) emission peak was observed at $3.26 \mathrm{eV}$, while the deep level emission at $2.48 \mathrm{eV}$ which is related to oxygen vacancy [4-10].

In order to characterize the crystallinity of $\mathrm{ZnO}$ thin films, XRD analyses were performed and the results are shown in Fig.4. From the XRD spectrum for the sample grown with the flow rate of $6 \mathrm{~L} / \mathrm{min}$, c-plane $\mathrm{ZnO}(002)$ at $31.7^{\circ}$, r-plane (101), m-plane (002) at $66.3^{\circ}$ and sapphire (100) diffraction peaks were shown. But the other two samples grown with flow rates of $8 \mathrm{~L} / \mathrm{min}$ and $10 \mathrm{~L} / \mathrm{min}$ possess m-plane (100), m-plane (200) and sapphire.
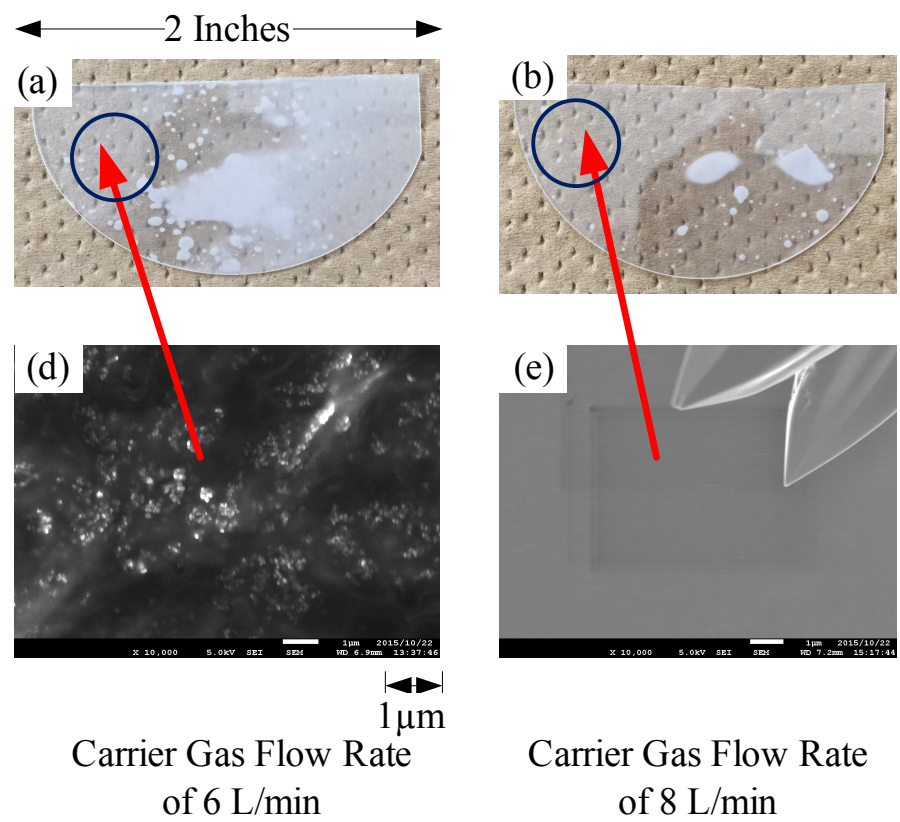

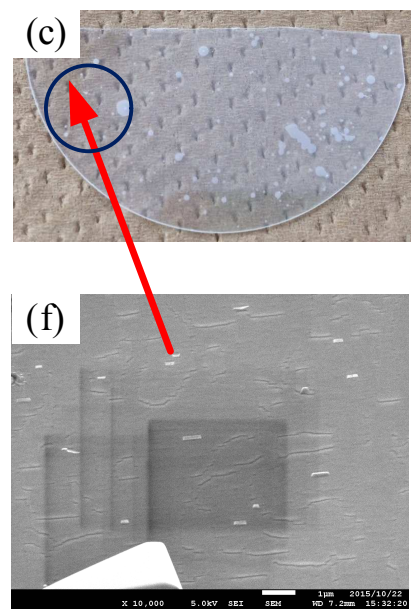

Carrier Gas Flow Rate of $10 \mathrm{~L} / \mathrm{min}$

Fig. 2. Photograph and SEM Images are Shown in (a)-(c) and (d)-(f), Respectively. 


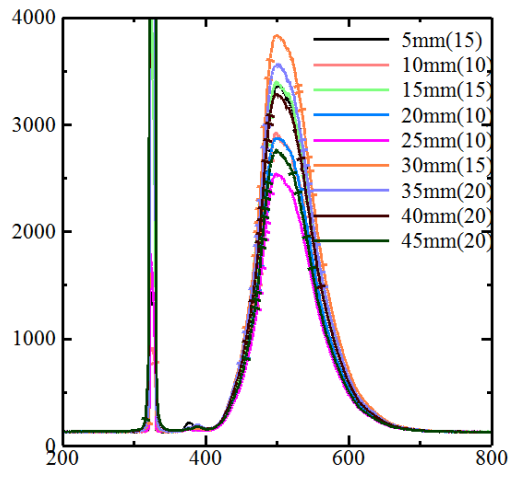

(a) Carrier Gas Flow Rate of $6 \mathrm{~L} / \mathrm{min}$

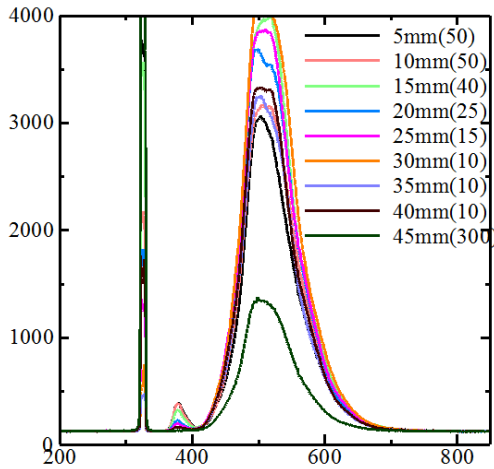

(a) Carrier Gas Flow Rate of $8 \mathrm{~L} / \mathrm{min}$

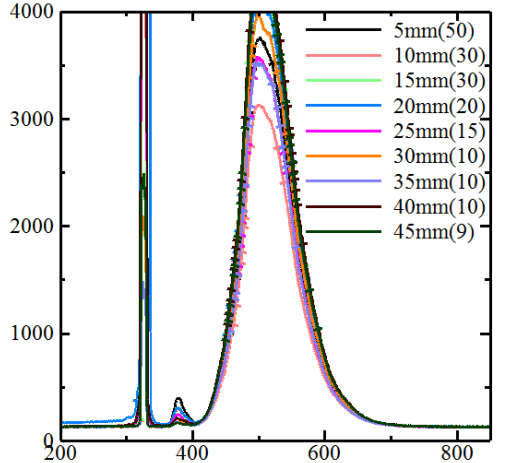

(a) Carrier Gas Flow Rate of $10 \mathrm{~L} / \mathrm{min}$

Fig. 3. Photoluminescence Spectra for the Samples Grown with Carrier Gas Flow Rate of (a) $6 \mathrm{~L} / \mathrm{min}$, (b) $8 \mathrm{~L} / \mathrm{min}$ and (c) $10 \mathrm{~L} / \mathrm{min}$.

The film thickness results are shown in Fig.5. When the clod mist come into the furnace, then the temperature of the mist increase with the location on the substrate. So, the thickness increases with the location because the thermal reaction is enhanced by the mist temperature. When we increased the flow rate from $8 \mathrm{~L} / \mathrm{min}$ to $10 \mathrm{~L} / \mathrm{min}$, the decomposition of the mist is decreased because the temperature of the mist is not increased at the high flow rate. According to these responses, the crystal growth condition for the sample grown with the carrier gas flow rate of $8 \mathrm{~L} / \mathrm{minis}$ was found to be optimal. The summary table for experiment is given in Table II.

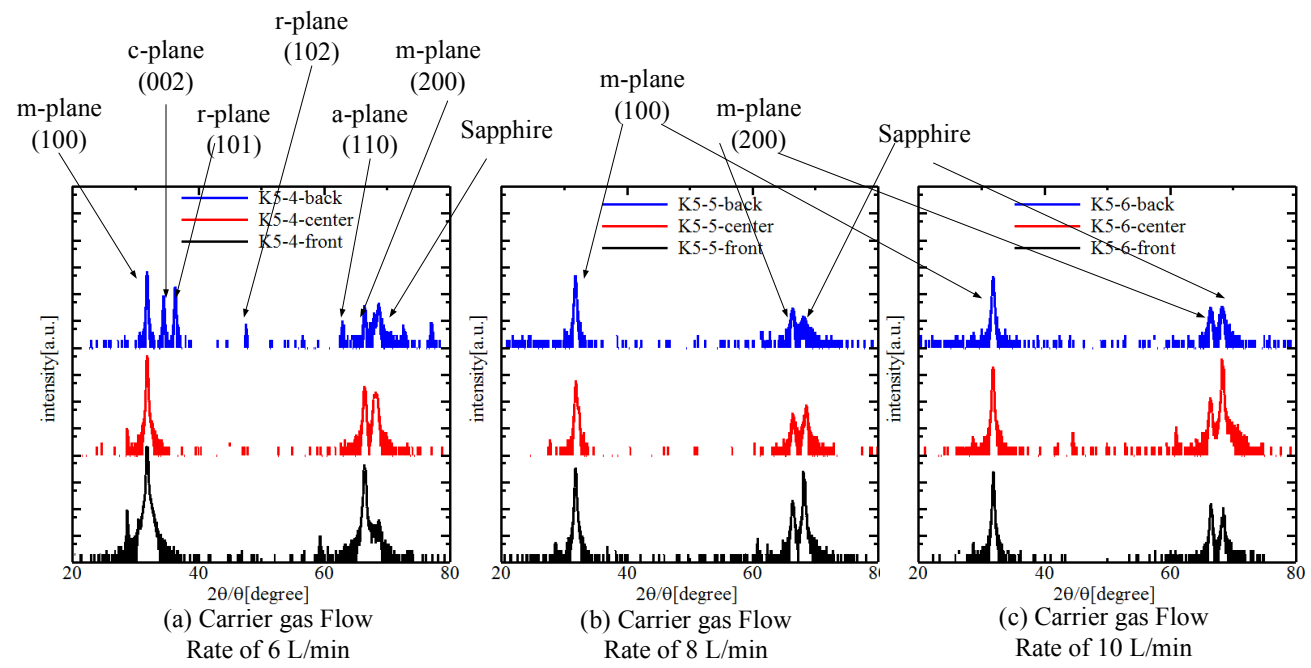

Fig. 4. XRD Spectra for the Samples Grown at Various Flow Rates.

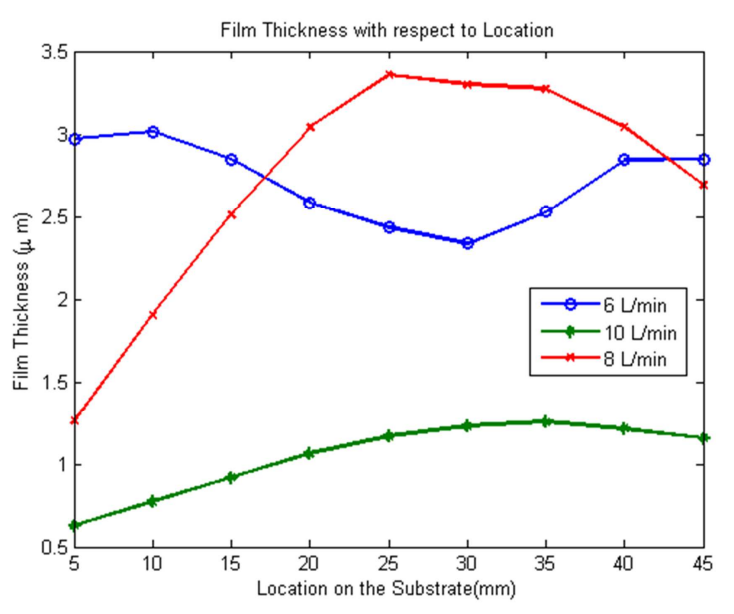

Fig. 5. Film Thickness Measurement for $550^{\circ} \mathrm{C}, 600^{\circ} \mathrm{C}$ and $650^{\circ} \mathrm{C}$.

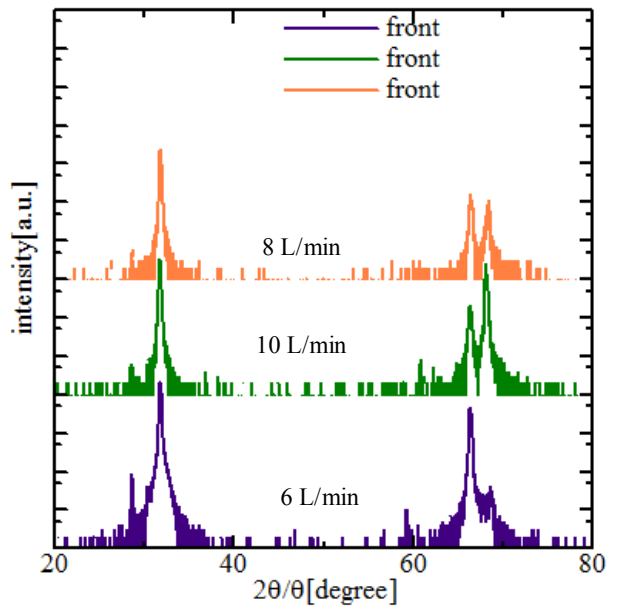

Fig. 6. PL Measurement for Front Side of the Sample on $550^{\circ} \mathrm{C}, 600^{\circ} \mathrm{C}$ and $650^{\circ} \mathrm{C}$. 
Table II. Summary for Experiment.

\begin{tabular}{lllll}
\hline & Film Thickness & PL & SEM & XRD \\
\hline $61 / \mathrm{min}$ & Large & Weak & Rough & Multi-peak \\
$81 / \mathrm{min}$ & Large & Strong & Flat & Multi-peak \\
$101 / \mathrm{min}$ & Small & Weak & Flat & Only m-plane \\
\hline
\end{tabular}

\section{Conclusion}

In this paper, undoped $\mathrm{ZnO}$ grown on sapphire by mist-CVD technique has been characterized. The undoped $\mathrm{ZnO}$ on m-plane sapphire was growth with different flow rate of carrier gas at $600^{\circ} \mathrm{C}$. From the PL measurement, weak near-band-edge (NBE) emission peak was observed at $3.26 \mathrm{eV}$ while the deep level emissions were very strong. Film thickness decreased with the flow rate. According to this experiment, the optimum values for mist CVD techniques of undoped $\mathrm{ZnO}$ with m-plane sapphire are substrate temperature of $600{ }^{\circ} \mathrm{C}$ and the carrier gas flow rate of $8 \mathrm{~L} / \mathrm{min}$. In this work, we found the optimum condition for crystal growth of $\mathrm{ZnO}$ on $\mathrm{m}$-plane sapphire and single orientation of $\mathrm{m}$-plane $\mathrm{ZnO}$ was observed by XRD $\theta-2 \theta$ scanning mode.

\section{Acknowledgements}

The authors sincerely acknowledge Dr. Hiroshi Shirakawa for valuable discussions. This work is supported for EEHE Project from Japan International Cooperation Agency (JICA).

\section{References}

[1] Kyu-Hyun Bang, Deuk-Kyu Hwang, Min-Chul Park, Young-Don Ko, Ilgu Yun, Jae-Min Myoung, Appl. Surf. Sci 210(2003) 177-182.

[2] J.G. Lu, T. Kawaharamura, H. Nishinaka, Y. Kamada, T. Ohshima, S. Fujita, J. Crystal Growth 299(2007)1-10.

[3] Toshiyuki Kawaharamura, Hiroyuki Nishinaka, and Shizuo Fujita, Jpn. J. Appl. Phys. Vol.47, No.6, 2008, pp. 4669-4675.

[4] N. Fujimura, T. Nishihara, S. Goto, J. Xua, T. Ito, J. Cryst. Growth 130(1993)269.

[5] Atsushi Tsukazaki, Akira Ohtomo, Takeyoshi Onuma, Makoto Ohtani, Takayuki Makino, Masatomo Sumiya, Keita Ohtani, Shigefusa F. Chichibu, Syunrou Fuke, Yusaburou Segawa, Hideo Ohno, Hideomi Koinuma And Masashi Kawasaki, Nature Materials, VOL 4, JANUARY 2005, pp-42-46.

[6] Shuji Nakamura, Masayuki Senoh, Shin-ichi Nagahama, naruhito Iwasa, Takao Yamada, Toshio Matsushita, Hiroyuki Kiyoku and Yasunobu Sugimoto, Jpn. J. Appl.Phys. Vol.(35)(1996) p.74-76.

[7] K. Nakahara, S. Akasaka, H. Yuji, K. Tamura, T. Fujii, Y. Nishimoto, D. Takamizu, A. Sasaki, T. Tanabe, H. Takasu, H. Amaike, T. Onuma, S. F. Chichibu, A. Tsukazaki, A. Ohtomo, and M. Kawasaki, Applied Physics Letters 97, 013501 (2010); doi: 10.1063/1.3459139.

[8] Kenji Yamamoto, Takako Tsuboi, Toshiya Ohashi, Takehiko Tawara, Hideki Gotoh, Atsushi Nakamura , Jiro Temmyo, Journal of Crystal Growth 312 (2010) 1703-1708.

[9] F. Urbach, Phys. Rev. 92 (1953) 1324.

[10] R.J. Elliott, Phys. Rev. 108 (1957) 1384. 